\title{
From the Editor
}

\section{Pete Smith University of Texas-Arlington}
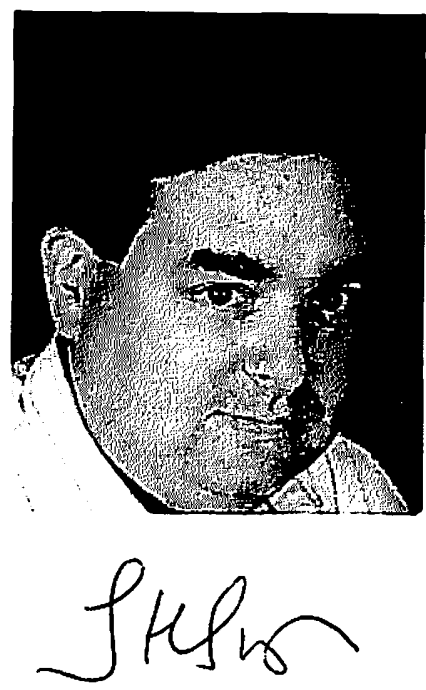

As much as we in the language technology field look forward to the future, I will remember 1996 more as a year of looking back, a time of memories and contemplation. No sooner than we as an IALL family have begun to fully comprehend the loss of Bob Henderson and, hopefully, to draw strength from our memories of him, than we are faced with another loss of monumental significance- the passing of Marie Sheppard, my predecessor at the IALL Journal.

Marie first came into my life with a telephone call back in 1994. She was searching, as always, for IALL members to help with the Journal. She talked quite passionately about the benefits of working for such a publication, and within about ninety seconds she had convinced me to join her.

Over the next two years, I slowly began to appreciate the immense love that Marie had for the Journal, as well as the artistry and intellectual power that shaped the Journal during her tenure. Those who have watched an artist at work know well the power and vividness of the creative act, and I was blessed to watch such a talent at work in Marie. It wasn't always easy to see her efforts or even for me to appreciate them fully at first. Marie worked in Colorado, and I in Texas. As then Managing Editor, I had many of the less artistic tasks to fulfill-work with a printer and bulk mailing to name two. If an issue was delayed a few days, or even a few weeks, I would wonder what could possibly be taking so long. And frequently, I must admit, when issues did come my way I was more absorbed in the printing and mailing details more than I should have been, and too often was not able to appropriately appreciate Marie's efforts at the time.

When I took my current post in 1996, I began immediately to rediscover her artistry. Part of my time that first year as Editor was taken up pouring over Marie's corpus as an editor, now with a new eye for her art and a deeper understanding. I continue to read and reread her Journal issues, and was coincidentally doing so the day I received word of her passing. 
I know of few compliments more telling of a writier or editor than to say that her work is worthy of serious study and appreciation.

I met Marie personally only twice. Once we had ice cream together at D/FW Airport, which is only a few miles from my campus, when she had a long layover during a trip. During that visit and together with her at Notre Dame in 1995, I was able to get to know her personally. Those times, along with the hundreds of emails and countless phone calls instilled in me a further appreciation for Marie: as a kind and good soul. It is one thing to be an artist of calibre, but it is quite another to blend that talent with human kindness and self-deprecation. Many IALL members would not have recognized Marie on the sidewalk, so quietly and carefully she worked. I remember our meetings fondly and they certainly give me golden memories of her.

And now we as an organization move into a new year. As all of us age and, hopefully, grow wiser, loss of friends and colleagues becomes more common. With age I hope, too, comes a greater ability to contemplate and appreciate the past and those we leave behind, with hopes that our contemplation help celebrate the beauty that was their lives and that is their legacy. I think that I for one may spend a good part of 1997 looking back as well. 